\title{
El asiento de los canónigos: sillas, honor y patronato en el siglo xVIII novohispano
}

\author{
David Carbajal López ${ }^{1}$ \\ davidclopez@hotmail.com
}

The seat of the canons: chairs, honor and Patronage in New Spain during the 18th century

\section{Resumen}

Las sillas para los canónigos que se colocaban en los presbiterios fueron materia de diversas querellas en las ciudades novohispanas del siglo XVIII. En esos alegatos, las sillas eran símbolo de jerarquías religiosas, entre seglares y clérigos y entre órdenes, pero sobre todo de jerarquías políticas, pues construían el predominio de los canónigos sobre los otros actores del mundo urbano novohispano. El Patronato fue invocado también, pero la Corona nunca llegó a intervenir de manera clara en esas querellas.

Palabras claves: ceremonias, reformas borbónicas, clero, canónigos, liturgia.

\section{Abstract}

The seats placed in the presbyteries for the canons were issue of various disputes in the cities of New Spain in the 18th century. Within these conflicts, the seats represented a symbol of religious hierarchy between laypersons and clergymen, as well as between clerical orders. Above all, these seats were seen as representative political hierarchies, since they constituted the predominance of the canons over other actors in the urban New Spanish world. Although, the Royal Patronage was also invoked, the Crown never intervened clearly in such disputes.

Key words: ceremonies, bourbon reforms, clergy, canons, liturgy.

1 Universidad de Guadalajara, Centro Universitario de los Lagos, México. Av. Enrique Díaz de León 1144. Col. Paseos de la Montaña. C.P. 47460 Lagos de Moreno, Jalisco, México. 
En la mañana del 15 de octubre de 1757 debía tener lugar en la iglesia del convento del Carmen de la ciudad de Valladolid de Michoacán la celebración anual que los religiosos dedicaban a Santa Teresa de Ávila, su fundadora y además patrona jurada de la urbe (Mazín, 1991, p. 29). Eran más de las nueve y media de la mañana, todo estaba listo en la iglesia: el Santísimo Sacramento estaba expuesto en el altar mayor, alrededor del cual se habían dispuesto dignas sillas para el deán y Cabildo Catedral, mientras que abajo del presbiterio, del lado del Evangelio, estaba dispuesta la banca forrada para el Ayuntamiento, encabezado por el alcalde mayor de la provincia. Estaba ya dispuesto el escenario, religioso y político, en que se desarrollaría la función.

El prior del convento, cumpliendo con su deber de cabeza de comunidad, salió a las puertas de la iglesia para recibir, con las cortesías correspondientes, a los canónigos y prelados de otras órdenes, mientras que los munícipes, llegados bajo de mazas, "entraban juntos hacia la sacristía", pues no era costumbre saludarlos de manera particular. Esto es, comenzaba el bien sabido despliegue de gestos, palabras y objetos que formaban parte fundamental del ritual público de la época, y que contribuían a fijar constantemente ante la sociedad las jerarquías del antiguo régimen (Fogel, 1989, p. 18). Entonces, según palabras del mismo prior, tuvo lugar el "aparecimiento clandestino" del alcalde mayor, don Martín de Reynoso, caballero de Calatrava. En lugar de dirigirse a la banca forrada, "se subió su merced al presbiterio y hecha adoración al Santísimo Sacramento, se hincó enfrente de la primera silla de las que estaban puestas [...] para el señor deán y prebendados de esta Santa Iglesia y hecha oración se levantó y sentó en dicha silla". ${ }^{2}$

El gesto del magistrado real tomó por sorpresa a los frailes y prebendados. Los canónigos lo calificaron de "acción tan extraña sin que hubiese antecedido prevención o urbana conferencia". En los minutos que siguieron, no hubo forma de que el alcalde abandonara la silla de la que se había apropiado, y que era además, repetimos, la primera, la que había de corresponder al deán, cabeza del Cabildo Catedral. Según la certificación redactada por el escribano que acompañó al magistrado, se realizaron al menos cuatro intentos para alejarlo de ella. Primero, a través de los carmelitas, los canónigos le ofrecieron trasladarse a la segunda silla, reconociendo su privilegio de caballero de Calatrava de sentarse entre los prebendados. Ante su negativa, "habilitaron" como prosecretario a un AGI, México, leg. 2662, "Testimonio de los autos de fuerza seguidos por D. Martín de Reynoso Mendoza", ff. 25-28, 55v-57. Todas las citas proceden de esta referencia hasta nueva llamada. 
clérigo, el licenciado José Manuel de Mafra, para que pasara a intimarle dejara la silla. Tres veces debió subir Mafra al presbiterio y otras tres bajó sin conseguir su objetivo, mas en la última llevó ya la máxima pena de los canónigos: la excomunión.

Excomulgado quedó pues el alcalde, pero siempre sentado en la silla que había defendido con tanto ahínco, mientras los carmelitas procedían a reservar el Santísimo. Desde luego, no es que el magistrado procediera de manera irracional, en las cuatro ocasiones en que se le intimó la retirada respondió con firmeza con un argumento que no era extraño entonces: estaba ahí aposentado "en defensa y guarda del Real Patronazgo de Su Majestad, con la mira de que no se vulnerasen sus reales prerrogativas". Regalía de la Corona a la vez que privilegio pontificio, como se sabe bien, el Patronato permitía al rey intervenir en la creación de iglesias y en la provisión de beneficios (Murillo, 2004, pp. 288-291), pero tenía también una dimensión ritual que se ha destacado menos en la historiografía.

El escándalo de la función de Santa Teresa en la iglesia del Carmen de Valladolid fue, hasta donde sabemos, el más sonoro pero no el único de los problemas suscitados a lo largo del siglo XVIII por el asiento de los canónigos novohispanos fuera del coro de sus catedrales. En este artículo nos dedicamos a examinar cuatro de esas querellas, ocurridas en Guadalajara en los albores de la centuria, en Valladolid de Michoacán en 1757, en Puebla de los Ángeles una década más tarde, y en la ciudad de México en el transcurso del último tercio del siglo. Desde luego, nos interesa resaltar los argumentos que se movilizaban en defensa o para apropiarse de sillas en los presbiterios. Las controversias se plantearon además lo mismo con un obispo en Guadalajara, con un magistrado real en Valladolid, con el ayuntamiento en Puebla y con otro cabildo clerical, el de la Colegiata de Nuestra Señora de Guadalupe del Tepeyac en México. Esto es, nos ofrecen la oportunidad de examinar las diversas facetas de las ceremonias en que participaban los canónigos de la época y, por tanto, la manera en que estas corporaciones hacían política. Debemos insistir en ello para cerrar esta introducción, siguiendo trabajos que se han realizado para otros periodos (Cañeque, 2004, pp. 610-611); el tema del uso de las sillas en el presbiterio no era banal en la medida en que las ceremonias no eran sólo una vía de legitimación, sino el ejercicio mismo del poder que contribuía a la construcción de lo social.

\section{Cánones, leyes y costumbres}

Al tratar del asiento de los canónigos, podría pensarse de inmediato en el espacio que les estaba asignado en las iglesias, el coro, su espacio por 
definición, donde dignidades y prebendados cumplían con el rezo y canto del oficio divino, es decir, las horas canónicas, conforme a los documentos fundamentales de sus respectivas iglesias. Desde luego, los asientos se distribuían conforme a la jerarquía de los propios canónigos, y subían y bajaban de ellos conforme lo requerían las ceremonias cotidianas.

Un segundo espacio en que los canónigos tomaban asiento era la sala capitular, donde celebraban las sesiones de cabildo y donde de nueva cuenta la distribución de los sitiales era conforme a su jerarquía. Debemos subrayarlo, las sillas eran un símbolo de especial importancia para los canónigos, hasta el punto que tomar posesión de sus prebendas era tanto como tomar el asiento. En efecto, en el caso de Nueva España, el Tercer Concilio Provincial de 1585 había establecido unos estatutos que, según especialistas en estas corporaciones, servían de "texto jurídico fundamental para el conjunto de los cabildos novohispanos" (Mazín, 1996, p. 85). En ellos se establecía claramente que "en señal de posesión", los nuevos integrantes, después de presentar sus documentos y prestar los juramentos correspondientes, debían ser llevados por dos capitulares al coro para colocarlos "en la misma silla de la dignidad, canonicato o ración", y otro tanto debía hacerse en la sala capitular (Estatutos, 1859, p. LIV).

Ahora bien, los canónigos no sólo se ocupaban de sus propias sillas, sino además y de manera muy particular de la silla episcopal. El Tercer Concilio Mexicano, siguiendo al Concilio de Trento, había establecido que los obispos "ocupen el primer asiento y el lugar que ellos mismos eligieren en el coro, en el cabildo, en las procesiones y en cualquiera otros actos públicos" (Concilio, 1859, p. 118). Esa silla era de alguna forma asunto de los canónigos de las catedrales en la medida en que eran ellos quienes daban a los obispos posesión de ella. De hecho, el primer punto que trataban los Estatutos de la Iglesia de México eran las ceremonias que los capitulares debían realizar cuando un nuevo prelado "personalmente o por procurador viniere a tomar posesión de su silla". Así como a los prebendados, los obispos, luego de prestados los juramentos del caso, irían al coro y luego volverían a la sala capitular para que en uno y otro sitio dos canónigos los entronizaran (Estatutos, 1859, p. XLIV).

Casi sobra decir que el asiento de los obispos estaba muy por encima en jerarquía del asiento de los canónigos, según dejaba claro el Caeremoniale Episcoporum. Fuera en el coro o en el presbiterio del lado del Evangelio, debía colocarse sobre tres gradas, in modum cathedrae, recubierto de dosel o baldaquín (Caeremoniale, 1837, p. 46). Los Estatutos de la Iglesia de México hablaban al menos de "sitial con cojines" para la silla en la sala capitular, e incluso para el procurador del obispo entrante 
se incluían "tapete [...] y cojín a los pies" (Estatutos, 1859, pp. LXII-LXIII). Mas salgamos ya de coro y sala capitular y vayamos al presbiterio y altar. En las ceremonias pontificales los canónigos debían asistir al obispo, regiamente entronizado, revestidos de los ornamentos propios de presbíteros y de diáconos, pero sentados en sencillos taburetes sin mayor adorno (Caeremoniale, 1837, pp. 22). En materia de asientos, la dignidad del obispo prácticamente opacaba la de los canónigos en esas celebraciones solemnes.

Aquí nos interesan además los asientos más allá de esos dos espacios que les estaban reservados. Era, en efecto, cuando los canónigos salían no sólo de sus coros y salas de cabildos, sino de sus catedrales, cuando no era tan obvio que pudieran disponer de sillas, y cuando éstas se enfrentaban a los asientos de otras autoridades. Ya la Erección de la Iglesia de México había contemplado esta posibilidad: al salir solemne y procesionalmente rumbo a otra iglesia "para asistir a los Divinos Oficios", los canónigos debían dar testimonio de "honestidad eclesiástica" (EStatutos, 1859, p. LXXIV). Ésta no sólo se mostraba en "los más preciosos ornamentos" que debían portar, sino también en el "lugar competente y asiento" en que habían de situarse en esas otras iglesias (Estatutos, 1859, p. LXXV).

Destaquemos que la Erección hablaba en concreto de "escaños" junto con tapetes para "que el Cabildo se siente por su orden", aunque también se mencionaban "sillas", en las cuales no "se atrevan a sentarse algunas personas seculares ni aun eclesiásticas" (Estatutos, 1859, p. LXXV). Ahora bien, no sólo los documentos fundacionales, concilios y libros litúrgicos regulaban el asiento de los canónigos; también debía tenerse presente la legislación real y, de manera muy particular, la costumbre. Una y otra reconocían también que fuera de sus catedrales, dignidades y prebendados podían distinguirse no sólo con taburetes o bancas, sino específicamente con sillas. Mas la real cédula de 1622 incluida en la Recopilación de leyes de Indias (1680) establecía una condición muy clara en la materia: los cabildos eclesiásticos no debían sobrepasar a los tribunales reales, las Reales Audiencias. ${ }^{3}$

Esto es, la ley en cuestión formaba parte de un extenso corpus de disposiciones en materia de asientos en las iglesias que nos recuerda la importancia política que tenían en la monarquía hispánica y que ya ha sido señalada, sobre todo para el siglo XVII (Cañeque, 2004). No era una casualidad que la primera de las leyes en materia de preeminencias y cortesías incluida en la Recopilación (1610) establecía que los virreyes

3 Recopilación de las leyes de los reynos de las Indias, libro III, tít. 15, ley xxxxvI. 
debían de sentarse en sitial en las iglesias, bien que la tercera ley, que databa de 1619, concedía el sitial a los obispos conforme al ceremonial. ${ }^{4}$ La legislación evidenciaba cierta sensibilidad por la jerarquía en materia de los asientos de las autoridades seculares. Si a los virreyes, como a los obispos, tocaba un sitial, a los gobernadores nombrados por el rey correspondía una silla con alfombra y almohada, y a los oidores sillas, pero sin almohadas, y a los "vecinos honrados", y por tanto a los ayuntamientos, bancos. En principio, el asiento en la iglesia era un privilegio de los magistrados reales y públicos, así como de los nobles y vecinos notables, de forma que en las leyes se establecía que "a ninguna otra persona se consienta llevar silla a la iglesia". ${ }^{5}$ Además, la Recopilación incluía también otra real cédula (1638), que reconocía la posibilidad de colocar sillas para los canónigos en sus catedrales, pero en un espacio adicional, el presbiterio, erigiéndose a la vez el monarca en protector de esos espacios sagrados. El rey prohibía "poner sillas a personas particulares" en ese lugar, por estar reservado "para los oficios divinos y prebendados" . ${ }^{6}$ De manera semejante, la legislación protegía también al coro de las catedrales. ${ }^{7}$

Destaquemos, por otra parte, que todas estas leyes se encontraban en el título 15 del libro III de la Recopilación, que trataba de las cortesías, y no en el título 6 del libro I, que trataba sobre el Patronato regio. Esto es, estrictamente según las leyes, se diría que las sillas no tenían nada que ver con el Patronato; empero, los comentarios de los juristas de la época señalaban que el patrono adquiría privilegios ceremoniales. Fue el caso de Antonio Joaquín de Rivadeneyra (1755, p. 35), quien siguiendo una tradición añeja del derecho canónico, citó un verso que aparecía ya en tiempos medievales en la Glossa Ordinaria: Patrono debetur honos, onor, emolumentum. Los comentaristas del siglo XVIII no eran unánimes en los honores precisos a que se refería ese verso, pero había al menos consenso en que incluía el honor del asiento.

Ahora bien, los términos precisos de la legislación no dejaban de tener alguna ambigüedad, dado que reconocían, además, la legitimidad de la costumbre local. Era así por ejemplo en el asiento de los gobernadores nombrados por el rey, pues en realidad la ley simplemente ordenaba "se guarde la costumbre". Otro tanto ocurría justo en el punto que aquí nos interesa: la igualdad de asiento en sillas de los canónigos con los oidores

\footnotetext{
4 Recopilación, libro III, tít. 15, ley I.

5 Recopilación, libro III, tít. 15, leyes I, XXV, XXVI, XVII, XVIII, XXXII, XXXIII.

6 Recopilación, libro III, tít. 15, ley xxxiIII.

7 Recopilación, libro III, tít. 15, ley xxxxvIII.
} 
en las iglesias distintas de las catedrales se mandaba respetar donde "hubiere costumbre". ${ }^{8}$

En suma, si bien el documento normativo general de las catedrales novohispanas establecía sillas para los canónigos fuera de sus iglesias, al igual que la mayor parte de los gestos y objetos que formaban el ritual político en la época, esos asientos se encontraban de por sí en situación ambigua. En la Erección se establecían sólo tratándose de la asistencia de los canónigos en cuerpo y no como particulares, la legislación real respaldaba el punto limitándolo a la costumbre ya existente, mientras que los comentaristas del derecho apuntaban al privilegio de los patronos de ocupar asientos de honor en las iglesias. Al final, por tanto, lo decisivo era la costumbre, que en efecto era una fuente de derecho no menos fundamental en la época (Murillo, 2004, pp. 282-287). Situadas en esta encrucijada de cánones, leyes y costumbres, esas sillas en los presbiterios de las iglesias de las capitales episcopales parecían ya predispuestas a ser materia de controversias, como las que analizaremos enseguida.

\section{La invención de la costumbre y \\ los límites del Ceremonial romano}

Entre las procesiones anuales que podían obligar a los canónigos a salir solemnemente de sus catedrales se contaba la procesión de letanías mayores de la fiesta de San Marcos evangelista. En el caso de la ciudad de Guadalajara a finales del siglo XVII y principios del siglo XVIII, la procesión se dirigía a la iglesia conventual de los franciscanos. Fue ahí, el 25 de abril de 1695, durante la sede vacante por muerte del obispo Juan de Santiago y León Garabito, que la Real Audiencia de Guadalajara notó por primera vez que el Cabildo Catedral tomó asiento en sillas "contraviniendo a leyes de estos reinos y a la costumbre inmemorial que siempre ha tenido de sentarse en su banca". ${ }^{9}$ Los oidores dirigieron una real provisión a los canónigos y prelados religiosos prohibiendo dicho asiento.

Como cabía esperar, el Cabildo Catedral reaccionó declarando que su asiento era "costumbre y posesión en que se halla de mucho tiempo a esta parte así en sede plena como en sede vacante", por lo que pidió a la Audiencia la revocación de la real provisión. El litigio se planteó ante todo para establecer cuál era realmente la costumbre, pues si bien los canóni-

8

9 AGI, Guadalajara, leg. 91, "Testimonio de los autos que se han formado sobre que el venerable deán y Cabildo...", ff. s/n. Todas las citas que siguen proceden de este documento hasta otra indicación. 
gos afirmaron que bastaba "con solos dos actos y aun con uno en opinión corriente", procuraron demostrar la antigüedad de la práctica, aunque no pudieron citar ejemplos de antes de 1694. Los oidores hicieron lo propio llamando a declarar a diversos prelados de las órdenes religiosas.

Además de seguir la controversia con el tribunal, los canónigos no cedieron un ápice en los hechos concretos. En la siguiente procesión de letanías, que iba al convento de San Agustín, el prior agustino obedeció a la Audiencia y mandó colocar banca en lugar de sillas para los canónigos, pero al salir a recibir el cortejo se encontró no sólo con la cruz procesional de la catedral, sino "que por delante de dicha procesión venían algunos de los sirvientes de dicha Santa Iglesia cargando sillas".

Llevado el caso ante el Consejo de Indias, en 1696 una real cédula mandó simplemente se atuviesen las partes al cumplimiento literal de la ley, lo que los canónigos estimaron como un triunfo. ${ }^{10}$ De hecho, cuando el litigio revivió entre 1707 y 1708, la Real Audiencia exponía que el Cabildo Catedral usaba, en los presbiterios de todas las iglesias de la ciudad, "doce sillas muy labradas" o "sillas bordadas", hechas en la ciudad de México. ${ }^{11}$ Los oidores, en cambio, según decía el fiscal del tribunal, habían tenido que "retirarse de tales congresos". ${ }^{12}$ Casi se diría que la costumbre "antigua" recién inventada de las sillas bordadas de los canónigos se había ido convirtiendo en símbolo del predominio del Cabildo Catedral en la ciudad, incluso sobre la autoridad episcopal.

El obispo Diego Camacho y Ávila hizo su entrada solemne a Guadalajara el 25 de marzo de 1707, después de haber sido arzobispo de Manila. Precisamente en el acto de su entrada, ante el arco triunfal colocado en una de las puertas laterales de la catedral, la comitiva se detuvo para escuchar a "dos niños [que] descifraron su dedicatoria", y mientras tanto, "se sentaron en sus sillas de brazos dichos señor venerable deán y cabildo, acompañando a dicho ilustrísimo señor". ${ }^{13}$ Ya desde ese momento los canónigos usaban el mismo asiento que el nuevo prelado, y en buena prueba de su pericia judicial, al día siguiente se expidió una AGI, Guadalajara, leg. 91, "Testimonio de los autos que se han formado sobre que el venerable deán y Cabildo...", ff. s/n., real cédula dada en Buen Retiro, 22 de junio de 1696.

11 AGI, Guadalajara, leg. 91, Real Audiencia de Guadalajara al rey, 26 de marzo de 1708 y AGI, Guadalajara, leg. 204, arzobispo-obispo de Guadalajara al rey, 24 de marzo de 1708. AGI, Guadalajara, leg. 204, certificación de 26 de marzo de 1707 anexa a representación al rey del Cabildo Catedral de Guadalajara, s/f. 
certificación de su asistencia en que se subrayaba que lo hacían sin "contradicción alguna a su antigua costumbre". ${ }^{14}$ Es decir, era una costumbre en realidad tan poco firme que ya tenían práctica de prepararse para defenderla.

Además, desde los primeros días de marzo el promotor fiscal había comenzado a levantar una información de testigos en que concluía lo mismo que argumentaban los oidores: los canónigos habían introducido las sillas aprovechando la sede vacante en 1694, por lo cual no había en realidad verdadera costumbre, y en consecuencia, la real cédula de 1696 no era argumento válido para su uso. ${ }^{15}$ En la catedral los canónigos usaban las sillas y las colocaban en el presbiterio al subir todos juntos a recibir las velas del día de la Candelaria, la ceniza al inicio de la cuaresma y las palmas el Domingo de Ramos. El propio arzobispo-obispo supo de boca del deán y del chantre que las utilizaban también en las ceremonias pontificales. Esto es, las usaban incluso delante del obispo, cuando, como el promotor fiscal insistió en recordar, debían estar usando como mucho "bancos de respaldo o escaños", según los cánones tridentinos.

Ahora bien, es interesante señalar que había un acuerdo muy particular entre los argumentos que el fiscal de la Real Audiencia reunió en contra de las sillas de los canónigos, y los que el propio Cabildo Catedral presentó a su favor contra el arzobispo-obispo. El primero declaró que el tribunal era competente "como quien ejerce y sustituye [...] el Real Patronato en el reino de la Nueva Galicia" ${ }^{16}$ Los canónigos, desde el 6 de marzo, pero en particular en su extensa respuesta de fines de junio de 1707 a las acusaciones fincadas por el promotor fiscal, afirmaron que "la potestad de conceder asientos en sillas [...] es regalía suprema que toca a los Católicos Reyes de España", en tanto que el monarca era "patrón universal de todas las Indias" ${ }^{17}$ El Patronato regio servía tanto para impugnar como para autorizar el uso de las sillas de los canónigos, más todavía, para éstos el patrono no había hecho sino respaldar la costumbre que ellos alegaban tener a su favor.

14

16

1

AGI, Guadalajara, leg. 204, certificación de 26 de marzo de 1707 anexa a representación al rey del Cabildo Catedral de Guadalajara, s/f.

AGI, Guadalajara, leg. 204, información anexa a la carta del arzobispo-obispo de Guadalajara al rey, 24 de marzo de 1708.

AGI, Guadalajara, leg. 91, “Testimonio de los autos que se han formado sobre que el venerable deán y Cabildo...", ff. s/n, parecer del fiscal de la Real Audiencia de Guadalajara, 23 de mayo de 1707.

AGI, Guadalajara, leg. 204, información anexa a la carta del arzobispo-obispo de Guadalajara al rey, 24 de marzo de 1708. 
Precavido, el arzobispo-obispo había preferido respetar la práctica de los canónigos en el presbiterio el Jueves y Viernes Santos de 1707, y no asistir a las funciones de letanías fuera de la catedral para dejar que los canónigos usaran libremente de sus sillas. ${ }^{18}$ Empero, ya desde su llegada el prelado comenzó a manifestar su propia postura en esta querella: la defensa de la implantación de los libros litúrgicos romanos, en particular el Ceremonial de los Obispos. El Cabildo Catedral respondió que éste no se hallaba en pleno vigor en las iglesias del reino de la Nueva España y dedicó el verano a confirmarlo, recabando información de las prácticas de las otras catedrales, en particular tres, las de México, Michoacán y Oaxaca.

Así, uno de los puntos interesantes de este caso es que nos confirma que, efectivamente, contra lo establecido en el Ceremonial de los Obispos, los habitantes de las ciudades episcopales de la Nueva España no solían ver a sus prelados sentados en trono en medio de bancos o escaños de canónigos. En la Metropolitana de México, el arzobispo se sentaba "sobre tarima elevada en medio de dichos cuatro señores [uno por cada clase del cabildo] en sus sillas y no en taburetes", un dignidad y un canónigo se revestían de diácono y subdiácono, pero tenían también "asientos en sillas al lado de la Epístola, y no en escaños". El maestro de ceremonias aclaraba que además eran "sillas de brazos", esto es, como lo diría claramente su homólogo de Valladolid de Michoacán al describir la misma práctica: "todos se sientan en sillas iguales con la de su señoría ilustrísima". Únicamente en la catedral de Antequera de Oaxaca estaban previstos taburetes para quienes hicieran de diácono y subdiácono, pero acaso porque era una función que tocaba, en principio, a los curas del Sagrario. ${ }^{19}$

En su respuesta de junio de 1707, los canónigos de Guadalajara insistieron no sólo en que las sillas eran de la jurisdicción del Patronato regio, y no del arzobispo-obispo, sino además en que ellos formaban con el prelado "un cuerpo para todo lo gubernativo y representativo de la Iglesia". Por tanto, lejos de perjudicar a la potestad episcopal el asiento de los canónigos le beneficiaba, pues lo hacía cabeza de "una comunidad tan grave y autorizada", en ese sentido "ni era conveniente ni fuera bien visto que las partes o miembros de él estuvieran sin la decencia corres-

18 AGI, Guadalajara, leg. 204, información anexa a la carta del arzobispo-obispo de Guadalajara al rey, 24 de marzo de 1708, en particular decreto del arzobispo-obispo, 27 de mayo de 1707, y AGI, Guadalajara, leg. 204, testimonio anexo a la representación al rey del arzobispo-obispo, 28 de marzo de 1708, f. 1.

19 AGI, Guadalajara, leg. 204, testimonio anexo a la representación al rey del arzobispoobispo, 28 de marzo de 1708, certificaciones en ff. 11-17. 
pondiente al ornato de la cabeza". ${ }^{20}$ A lo largo de la extensa controversia, además, insistieron varias veces en que no podían poner en riesgo "las loables costumbres de esta iglesia que tenemos juradas guardar". ${ }^{21}$ Empero, ya en esos días del verano de 1707 reconocieron asimismo que protegían el honor de su corporación y de sus integrantes; de hecho, cerraron su respuesta al promotor fiscal luciendo cuatro "mayores prerrogativas y honoríficos títulos" que formaban casi un verdadero panegírico de los cabildos catedrales. ${ }^{22}$

Los argumentos del arzobispo-obispo iban en el mismo sentido, pero desde luego, defendiendo el honor de su propia dignidad. En su primera carta al rey sobre el tema lo decía muy claro, el problema de las sillas en las otras iglesias era "motivo para discurrir el que no haya distinción entre súbditos y prelados". ${ }^{23}$ De ahí también su insistencia en hacer cumplir estrictamente el Ceremonial de los Obispos en lo que tocaba a los asientos en los pontificales. En anexo a su respuesta a los canónigos el 18 de abril de 1707 sobre lo que habría de hacerse el Jueves y Viernes Santos de ese año, insistió en la cuestión de la jerarquía que establecía el Ceremonial. Si "un cardenal, cuando celebra misa delante del Papa se sienta en un taburete sin respaldar [...] con mucha mayor razón se debe decir lo mismo de cualquier capitular", afirmaba el prelado, quien no dudaba en calificar como "corruptela o abuso" las sillas que tanto defendían los canónigos. ${ }^{24}$ Más aún, en diciembre de ese año, mientras realizaba su visita pastoral, en medio de abundantes citas del derecho canónico y hasta del tratado de jerarquías eclesiásticas del Pseudo Dionisio Areopagita, repetía que los libros litúrgicos eran claros en establecer "la exaltación, elevación, rendido obsequio y reverente asistencia de todos los eclesiásticos de cualquier calidad, condición y grado a la dicha dignidad episcopal". ${ }^{25}$

Largo sería presentar aquí todas las peripecias de esta controversia, cuyo final desconocemos, mas no puede dejar de constatarse, que aun si

20 AGI, Guadalajara, leg. 204, información anexa a la carta del arzobispo-obispo de Guadalajara al rey, 24 de marzo de 1708, ff. s/n.

21 AGI, Guadalajara, leg. 204, testimonio anexo a la representación al rey del arzobispoobispo, 28 de marzo de 1708, ff. 3-3v. AGI, Guadalajara, leg. 204, información anexa a la carta del arzobispo-obispo de Guadalajara al rey, 24 de marzo de 1708, ff. s/n. AGI, Guadalajara, leg. 204, arzobispo-obispo de Guadalajara al rey, 24 de marzo de 1708. AGI, Guadalajara, leg. 204, testimonio anexo a la representación al rey del arzobispoobispo, 28 de marzo de 1708, ff. 1-2. AGI, Guadalajara, leg. 204, testimonio adjunto a la carta del arzobispo-obispo al rey, 25 de marzo de 1708, ff. 1-10v. 
las sillas no hubieran estado bajo la jurisdicción del Real Patronato como decían oidores y canónigos, la propia ambigüedad de la costumbre, la legislación y los cánones terminaban llevando, en esos inicios del siglo XVIII, hasta a los más altos tribunales del rey los problemas del asiento del Cabildo Catedral de Guadalajara. Sin embargo, la Corona no se pronunció de manera clara en estos asuntos. Por ello conviene que volvamos ahora al ejemplo de Valladolid de Michoacán que citábamos al principio, así como al caso de la ciudad de Puebla unos años más tarde, para ver lo que fiscales y magistrados alegaron en el caso de la competencia en concreto con un magistrado real.

\section{Protección de los espacios sagrados y diferencias de interpretación}

En Valladolid de Michoacán y más tarde en Puebla de los Ángeles (Ramos, 2010), las controversias en materia de sillas de los canónigos no eran muy distintas, al menos en apariencia. Ya hemos visto que el alcalde mayor se aferró a la silla -literalmente- en el presbiterio de la iglesia del Carmen, alegando que defendía el Patronato regio. En realidad el incidente del día de Santa Teresa no era el primero, de hecho, según un auto del propio alcalde mayor fechado el día 10 de octubre, "desde el ingreso a su empleo" había notado "lo abandonado que en un todo estaba la autoridad y dignidad de esta dicha nobilísima ciudad". "Autoridad y dignidad" se asociaban específica y estrechamente a los honores en la iglesia, tanto en la catedral como en las demás de la ciudad. La cuestión era, de nueva cuenta, eminentemente política. El magistrado de inmediato agregaba que le correspondían más honores a él como "justicia mayor de ella y su provincia, y en quien está subdelegada la alta dignidad del Real Patronato de Su Majestad". ${ }^{26}$

Para solucionar ese problema el magistrado trató de negociar una mejora de honores con los eclesiásticos de manera particular. Fracasó con los canónigos, pero tuvo éxito con el prior de los agustinos y con el guardián de los franciscanos. Por ello, en los festejos de 28 de agosto y 4 de octubre, pudo presentarse a las respectivas iglesias encabezando al ayuntamiento bajo de mazas, y ser recibido con "agua bendita al entrar en su iglesia, banco vestido y [porta]paz" ${ }^{27}$ Fue entre este último festejo y el de

26 AGI, México, leg. 2662, "Testimonio de los autos de fuerza seguidos por D. Martín de Reynoso Mendoza", ff. 11-14.

27 AGI, México, leg. 2662, "Testimonio de los autos de fuerza seguidos por D. Martín de Reynoso Mendoza", ff. 9-11. 
Santa Teresa que la situación se complicó para el magistrado, de forma harto singular cabe reconocer. En la función del 4 de octubre, el Cabildo Catedral se negó a asistir, pero no a causa de un problema de asientos, sino por el portapaz, y el prior carmelita aparentemente fue presionado por los canónigos para no conceder ese honor al alcalde y ayuntamiento.

Esto es, en realidad el día 15 de octubre el caballero Reynoso estaba más bien tomando desquite por el desaire del portapaz, en las sillas de los canónigos. Éstas entraron a la controversia en el auto del alcalde del 10 de octubre, en que lamentó con cierta extensión la desigualdad entre el Cabildo Catedral y el ayuntamiento en las iglesias fuera de la propia catedral. En ellas, el problema no era sólo que se instalaran las sillas de los canónigos, sino que para ello era necesario colocar un tablado para ampliar el presbiterio, por lo que prácticamente se formaba un sitial alfombrado, cuya altura marcaba simbólicamente la diferencia de jerarquía entre ambas corporaciones, o al menos así lo lamentaba el magistrado: "mediante esto la ciudad y su merced en un banco debajo de dicho tablado, una vara poco más o menos". ${ }^{28}$ La protección del Real Patronato y del honor de su magistratura fueron pues los argumentos del alcalde mayor michoacano.

Una vez que el alcalde se atrevió a invadir el presbiterio y tomar la silla del deán, fue excomulgado, como decíamos. Pocos días después del incidente, el magistrado llevó el caso ante la Real Audiencia de México por la vía del recurso de fuerza. El 19 de octubre el tribunal dirigió una real provisión al Cabildo Catedral vallisoletano encargándole la absolución al alcalde mayor ad reincidemtiam, remitiendo el expediente para su examen. Ambas partes procedieron a reunir las pruebas de sus respectivos argumentos, los canónigos levantaron efectivamente la excomunión y ya el día 29 de octubre firmaron un informe dirigido a la Audiencia. En él reiteraban su versión del incidente, señalando que el punto central había sido el del portapaz, arguyendo a su favor las leyes de Indias y la costumbre, aunque para las sillas remitían -sin ser muy específicos-a los cánones del Concilio de Trento. No dejaron de advertir, además, implicaciones en la conducta del magistrado, temerario en su comportamiento por la presencia del "fácil vulgo a quien enciende en bandos perjudiciales a la república la menor centella". ${ }^{29}$ En suma pues, el Cabildo Catedral se limitó estrictamente a argumentos de orden político.

28

29 AGI, México, leg. 2662, “Testimonio de los autos de fuerza seguidos por D. Martín de Reynoso Mendoza", ff. 11-14. AGI, México, leg. 2662, "Testimonio de los autos de fuerza seguidos por D. Martín de Reynoso Mendoza", ff. 1-3 y 90-94v.

Letras Históricas / Número 17 / Otoño 2017-invierno 2018 / México / pp. 17-39 / ISSN: 2007-1140 
Paradójicamente, fue en la Real Audiencia donde el caso cobró algún significado religioso. El fiscal del tribunal comenzó su dictamen recordando la sacralidad del espacio donde había tenido lugar el incidente y remitiendo a la más remota tradición cristiana, cuando en los templos "nunca en ellos estaban sentados los legos". En particular se centró en el hecho concreto del alcalde Reynoso: se había sentado en el presbiterio cuando los cánones lo prohibían explícitamente a los seglares. Además, la legislación real era clara estableciendo la forma en que debían tomar asiento los magistrados en las iglesias, sin que los honores pedidos por el alcalde mayor estuvieran incluidos. Como siempre la costumbre resultaba también decisiva. Conforme a ella, el magistrado debía "gobernarse por lo que se hubiere practicado con sus antecesores". En conclusión, el alcalde "cometió una muy culpable falta de reverencia a aquel sagrado lugar, una pública y constante trasgresión de lo establecido por derecho canónico"; y como la autoridad facultada para castigar la falta era el Cabildo Catedral sede vacante, la excomunión estaba bien impuesta y no había razón para el recurso de fuerza. En auto de 28 de noviembre de 1757 la Real Audiencia agregó además que el argumento del Real Patronato no era válido, toda vez que "reside inmediatamente en los excelentísimos virreyes, presidentes y gobernadores de las provincias capitales de estos reinos", y no en un mero alcalde mayor. ${ }^{30}$

No sólo en la Real Audiencia de México se esgrimían estos argumentos. Algo semejante ocurrió una década más tarde con el ayuntamiento de Puebla en el Consejo de Indias. En marzo de 1767, los munícipes solicitaron en esa instancia el uso de sillas en las iglesias, pues, como en Valladolid de Michoacán, sólo disponían de una banca. ${ }^{31}$ Casi se diría que trataban de evitar quedar rezagados en materia de honores en un momento en que las otras autoridades de la ciudad las estaban reforzando: al mismo tiempo el gobernador poblano peleaba por el uso de silla con tapete y almohada en sus asistencias a las iglesias, y los canónigos habían colocado también sillas en los presbiterios de las iglesias, ${ }^{32}$ con lo que sólo ellos quedaban usando banca. Alegaron a su favor los méritos de la ciudad, más el fiscal del Consejo no quedó convencido, antes bien señaló como "cosa ajena de toda razón" que en las iglesias y para actos de

30 1767.

32 AGI, México, leg. 1269 y AGI, México, leg. 2662. 7767. Reynoso Mendoza", ff. 111-118v para el dictamen del fiscal y ff. 189v-190 para el auto. AGI, México, leg. 2662, representación del Ayuntamiento de Puebla, $1^{\circ}$ de marzo de 
"culto y religión" quedaran los sacerdotes sin "todas aquellas preeminencias que manifiestan su superioridad sobre los seglares". ${ }^{33}$

Ante los ayuntamientos, pues, y los magistrados reales incorporados en ellos, las sillas validaban la superioridad del clero en las iglesias fundada en razones religiosas. El ayuntamiento poblano, sin embargo, no cejó en su empeño, y en mayo de 1770 emprendió un nuevo intento en la materia reiterando uno de los puntos que habían herido la sensibilidad del alcalde mayor michoacano: el desnivel entre las sillas en el presbiterio de los canónigos y su banco a ras de suelo. Antes que sufrir esa humillación, los regidores preferían abandonar las asistencias públicas. No habiendo conseguido las sillas, esta vez trataron de obtener o bien que el Cabildo Catedral no usara de ellas cuando no asistía el gobernador civil, o bien que "se coloque en el coro o lugar donde se ponen los músicos y cantores". ${ }^{34}$

Como cabía esperar, fueron nuevamente desairados por el fiscal del Consejo para Nueva España, ${ }^{35}$ mas la real cédula que resultó de este expediente, fechada en 21 de julio de 1770, les ordenó cumplir literalmente una disposición anterior, del 10 de febrero de 1714, en que se había arreglado el uso de sillas entre el Cabildo Catedral poblano y alcalde mayor Juan José de Veytia, quien tenía honores de consejero de Indias. ${ }^{36} \mathrm{El}$ principio era simple: si asistía a la iglesia Veytia, usaba de silla y en consecuencia, los canónigos también, sólo que en ese último tercio del siglo XVIII los regidores poblanos interpretaron la real cédula a su favor. Como la última frase de la real cédula decía que alcalde y canónigos quedaban con sillas pero "sin alterar unos ni otros sus sitios y lugares [...] según el estilo y costumbre" vigente entonces, es decir vigente en 1714, los regidores alegaron que ese estilo era que los canónigos se instalaran en los coros de las iglesias. Evidentemente, fuera de la Catedral, los coros de las iglesias poblanas y de Nueva España en general, se ubicaban en alto sobre la parte más baja de las naves. Allá debían irse a instalar los canónigos, dejando despejado el presbiterio, y a los munícipes, en banca sobre las naves, pero al menos mostrándose primeras autoridades en la iglesia.

De esta ingeniosa forma los regidores hacían invisibles las "humillantes" sillas de los canónigos. Cabe advertirlo, sabemos que la real cédula

33

34

35

36

AGI, México, leg. 2662, dictamen del fiscal del Consejo, 8 de junio de 1767.

AGI, México, leg. 2662, representación del Ayuntamiento de Puebla por poder en Madrid, 29 de mayo de 1770.

AGI, México, leg. 2662, dictamen del fiscal del Consejo, 29 de junio de 1770.

AGI, México, leg. 2662, testimonio de la real cédula dada en Madrid, 10 de febrero de 1714. 
de julio de 1770 llegó a la Ciudad de México en octubre de ese mismo año, pues el gobierno del reino le dio el obedecimiento por decreto del virrey el 9 de noviembre. Mas sólo hasta mayo de 1773 el Ayuntamiento de Puebla procedió a hacerla cumplir, remitiéndola además al Cabildo Catedral. ${ }^{37}$ La querella llegó a su punto más alto en agosto de 1774, con motivo de la celebración de Santo Domingo de Guzmán en la iglesia de los predicadores. Cuando el ayuntamiento amenazó con no asistir si los canónigos no colocaban "sus asientos donde era costumbre el año de catorce", el deán respondió que colocarían escaños o sillas, según el caso, en el presbiterio "pues aquel lugar no era registerio sino presbiterio", insistiendo así en que no estaba bajo el control del ayuntamiento, sino que era espacio propio del clero. ${ }^{38}$

Los munícipes habrían de responder que, al quedarse con sus sillas en los presbiterios, los canónigos "dividían" su cuerpo, pues sus capellanes subían a los coros. ${ }^{39}$ Los canónigos defendieron su derecho a usar sillas en el presbiterio fuera de la Catedral, fundados en la propia real cédula de 1714, que también decía que debían hacerlo "como se observa y practica en las iglesias de México, Guadalajara y Michoacán" -en estas últimas, ya lo hemos visto, en efecto los canónigos se sentaban en sillas en el presbiterio-, y además, develando la interpretación a conveniencia que los regidores habían hecho de las dos cédulas reales. ${ }^{40}$ Los argumentos convencieron al fiscal José Antonio Areche, quien además mandó certificar la práctica del Cabildo Catedral de México, resultando efectivamente que los canónigos tomaban sillas en el presbiterio, tanto en concurrencia de la Real Audiencia como del ayuntamiento. ${ }^{41}$

En fin, el dictamen del fiscal Areche es interesante porque, ante un expediente en que se citaba a las principales catedrales del reino, no pudo sino reaccionar recomendando se informara al Consejo de Indias para que "se observen unas mismas ceremonias en semejantes asuntos" entre ayuntamientos y cabildos catedrales; es decir, que finalmente la

37 AGI, México, leg. 2662, “Testimonio de los Autos seguidos por parte del Cabildo, Justicia y Regimiento de la Ciudad de Puebla...", ff. 1-54v.

38

(1)

41 AGI, México, leg. 2662, “Testimonio de los Autos seguidos por parte del Cabildo, Justicia y Regimiento de la Ciudad de Puebla...", ff. 55-58.

AGI, México, leg. 2662, “Testimonio de los Autos seguidos por parte del Cabildo, Justicia y Regimiento de la Ciudad de Puebla...", ff. 59-64.

AGI, México, leg. 2662, “Testimonio de los Autos seguidos por parte del Cabildo, Justicia y Regimiento de la Ciudad de Puebla...", ff. 68-73.

AGI, México, leg. 2662, “Testimonio de los Autos seguidos por parte del Cabildo, Justicia y Regimiento de la Ciudad de Puebla...", ff. 73-83v. 
Corona estableciera unas reglas fijas en materia de asientos de canónigos fuera de la catedral en concurrencia con las corporaciones civiles. ${ }^{42}$ Mas justo eso es lo que no hizo el alto tribunal. El fiscal de la sección novohispana se limitó a advertir al virrey que todo caso semejante "se sustancie y delibere conforme a lo que se establece por las leyes". ${ }^{43}$ Así pues, aunque aquí encontramos nuevamente la dinámica que llevaba a plantear ante la jurisdicción real estas querellas, se diría que incluso en la época de las reformas el fundamento último de estos expedientes no era sino la costumbre y el derecho canónico.

Un último caso podía presentarse en materia del asiento de canónigos: la concurrencia ya no con obispos, oidores o munícipes, sino directamente con otros canónigos. Y tal fue la experiencia que debió afrontar el Cabildo Catedral Metropolitano de México tras la fundación del Cabildo de la Colegiata de Nuestra Señora de Guadalupe.

\section{Sillas, jerarquía y leyes fundamentales}

La primera ocasión en que hemos podido identificar que los canónigos de la catedral trataron en actas el tema de sus sillas fue el $1^{\circ}$ de octubre de 1781. Entonces refirieron tres ocasiones, aunque podían extenderse hasta cinco, en que los canónigos de la Colegiata habían competido con ellos por su uso. ${ }^{44}$ Lo interesante de las actas de los cabildos de los canónigos es que nos muestran las dudas que ofrecía el punto. Si bien resolvieron de inmediato promover un ocurso ante la Real Audiencia, en principio prefirieron consultar el asunto con el arzobispo, quien coincidió en la urgencia y gravedad, pero no les clarificó a quién debían recurrir en primer lugar. El doctoral señaló: "siendo el privilegio de las sillas dimanado solamente de ley real, y no haber canon ni ley eclesiástica que se las conceda a los canónigos [...] debe dirigirse a la Real Audiencia". Paradójicamente, el derecho canónico podía servir para garantizar la superioridad del clero ante la autoridad real y el derecho civil para sostener la jerarquía de la catedral frente a otros cuerpos eclesiásticos. En contraste, el arcediano propuso interponer recurso ante el arzobispo, "como juez natural en el asunto", mientras que el tesorero señaló que el problema no eran propiamente las sillas, pues tampoco debía tolerárseles un banco en los presbiterios, ni en general "la igualdad que quieren tener con los

\footnotetext{
42 AGI, México, leg. 2662, “Testimonio de los Autos seguidos por parte del Cabildo, Justicia y Regimiento de la Ciudad de Puebla...", ff. 83-83v.

43 AGI, México, leg. 2662, dictamen del fiscal del Consejo, 8 de agosto de 1775.

44 ACCMM, Actas de Cabildo, libro 54, f. 296.
} 
señores capitulares de este cabildo". Al final procedieron a pedir primero explicaciones al Cabildo de la Colegiata, las que en un primer momento surtieron efecto y retrasaron el recurso a la vía judicial. ${ }^{45}$

Es cierto que hubo otras autoridades eclesiásticas que causaron incidentes puntuales al ocupar sillas en el presbiterio ante los indignados ojos de los canónigos: prelados de los religiosos o cabezas de otras corporaciones, como la Universidad. ${ }^{46}$ Sin embargo, el problema fundamental siguió siendo el Cabildo de la Colegiata. La controversia resurgió en enero de 1796 con motivo de un entierro en la iglesia de la Merced, donde dos canónigos de la Colegiata tomaron incluso la silla del deán en el presbiterio, delante de uno de los canónigos de la catedral. ${ }^{47}$ Desde luego, la Colegiata fue de inmediato emplazada a dar explicaciones, y en esta ocasión sus canónigos aseguraron que contaban con una real cédula que los equiparaba en tratamiento a los de la catedral, fechada el 21 de julio de $1795 .{ }^{48}$

Una bella paradoja es que la cédula en cuestión era producto de una iniciativa de la propia Catedral Metropolitana. En mayo de 1793 el Cabildo Catedral se había dirigido al Consejo a través del virrey para solicitar autorización a fin de usar "bolillos", es decir, puños o bocamangas, "para distinguirse del resto del clero", conforme al uso de las catedrales del Perú. ${ }^{49}$ Aunque las gestiones al respecto se prolongaron hasta el año siguiente, no hubo mayor problema en la corte de Madrid para conceder este privilegio, que comenzaron a pedir también los canónigos de las otras catedrales, y lo propio harían en su momento los de la Colegiata. ${ }^{50}$ El doctoral de la catedral lo haría notar en su momento: la real cédula que citaban los canónigos de Guadalupe, si bien contenía efectivamente una cláusula equiparando sus privilegios a los de catedral, en realidad versaba sobre un tema distinto del de las sillas. De nuevo, pues, estamos ante una interpretación a conveniencia de las resoluciones regias; de nuevo, además, nos encontramos con que unos honores tendían a implicar otros, y de nuevo la jurisdicción del rey había de resolver el conflicto.

El doctoral de la Metropolitana se ocupó de redactar un extenso memorial para presentarlo a la Real Audiencia de México. Además de señalar,

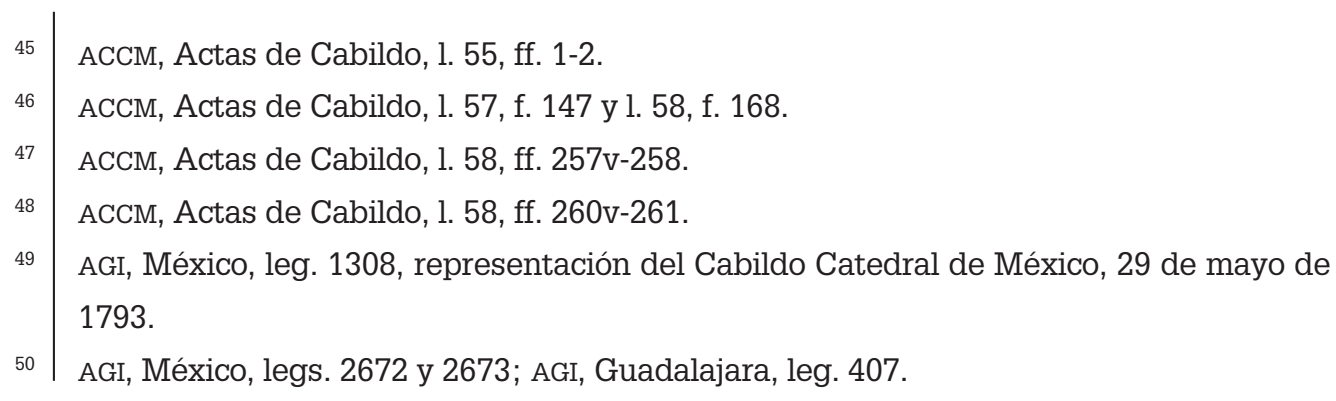


ya lo decíamos, el error de interpretación de los canónigos de Guadalupe - "siniestra interpretación" desde luego debida a su "desmedida ambición" o "capricho"-, presentó como eje fundamental de sus argumentos el respeto al principio de desigualdad jerárquica, tan propia del antiguo régimen, en varios sentidos. En principio, desigualdad entre los distintos tipos de derecho: no era lo mismo un privilegio que una ley fundamental. La concesión de "bolillos" a los canónigos de Guadalupe era, sin duda, un privilegio para ellos; en cambio, para los canónigos de las catedrales los asientos en los presbiterios eran parte de leyes fundamentales, tanto civiles como canónicas. La petición de los canónigos venía a constituir un intento de derogar "leyes públicas" y "privilegios incorporados en el derecho común", contra las reglas del derecho y con una cédula que ni siquiera contenía cláusulas derogatorias. ${ }^{51}$ En segundo lugar, y sin duda más importante, estaba la jerarquía eclesiástica, establecida en el derecho canónico, que directamente "aborrecía" la igualdad y que era defendida por el rey como monarca católico y patrono de la Iglesia. Destaquemos que en el parecer del doctoral, contrario a lo que hubiera podido deducirse a principios de siglo de los documentos del Cabildo Catedral de Guadalajara, el Real Patronato no parecía implicar sino el respaldo a la legislación canónica en materia de sillas, y no una facultad arbitraria para otorgar o negar su uso. Esto es, incluso si el rey hubiera otorgado el privilegio de las sillas a la Colegiata, la concesión hubiera sido ilegítima por situar en el mismo nivel a ese cabildo con los cabildos catedrales. El parecer del doctoral era un extenso alegato de la desigualdad entre unos y otros, tratando de agotar todos sus aspectos. El texto, redactado ya en los últimos años del siglo, evocaba negativamente el ejemplo de la Francia revolucionaria, único lugar donde podría "tolerarse semejante igualdad". En cambio, "con un monarca católico y en país donde gobiernan las decisiones canónicas" se entendía que la desigualdad y la jerarquía constituían el buen orden y, en ese sentido, entre ambos tipos de canónigos reinaba "la diferencia que media entre la primera clase del estado eclesiástico y la segunda, entre el superior y el inferior".

El doctoral volvería varias veces sobre este punto, haciendo uso también de argumentos históricos. La "disciplina antigua" era la que había ido construyendo, desde el siglo $\mathrm{v}$, la preeminencia de los canónigos de las catedrales, a los cuales ningún otro clérigo podía equipararse. Reaparece aquí constantemente un argumento que ya hemos visto en Guadalajara, el de que los canónigos formaban cuerpo con el obispo, y con éste

51 ACCM, Actas de Cabildo, 1. 58, ff. 297-311, todas las citas que siguen corresponden a este documento hasta nuevo llamado.

Letras Históricas / Número 17 / Otoño 2017-invierno 2018 / México / pp. 17-39 / ISSN: 2007-1140 
ejercían "habitual jurisdicción", que implicaba a su vez un tratamiento de honor particular.

Los canónigos de Guadalupe habían propuesto que, en concurrencia con los de la catedral, en las otras iglesias de México podían ocupar las sillas que solían usar los canónigos de otras catedrales cuando estaban de visita en la ciudad. Esta idea sirvió en el parecer para comprobar que pretendían equipararse a una clase que no les correspondía ("no son del mismo grado y carácter", sentenció el doctoral) y llevar un privilegio puntual más allá de sus límites. El doctoral afirmaba que no podían usar de él "fuera del territorio de su residencia", los canónigos de las otras catedrales lo hacían "en virtud de la hermandad que media entre todas las catedrales", de la que obviamente los de la Colegiata no formaban parte; frente a los canónigos de las catedrales, si querían "tener algún lugar", éste "siempre sería el último".

Debía considerarse asimismo la desigualdad en méritos, es decir, en "servicios que han hecho al rey y al público". En esa segunda mitad del siglo XVIII novohispano, si una autoridad había requerido apoyo de las arcas de las catedrales había sido, en efecto, la Corona; asimismo, podían presumir también de haber atendido "necesidades públicas" en epidemias y hambrunas. Por el contrario, la colegiata, "lejos de servir al público y particulares, más bien los incomodan con las repetidas limosnas que piden", hasta el punto que "más bien parecen frailes mendicantes que canónigos". De inmediato el doctoral acotó que la pobreza también tenía mérito, pero sólo "en la otra vida", mas lo que interesa resaltar es que los honores en las iglesias terminaban siendo, también para los canónigos, la retribución a la utilidad pública (en el sentido tradicional del término "público": Lempérière, 1998) que prestaban sus cuerpos. ${ }^{52}$

En fin, venía a cuento también la historia concreta de la Colegiata de Guadalupe, que el doctoral presentaba como profundamente opuesta al respeto de esos principios. "Estos vínculos que pide el orden jerárquico de la Iglesia han procurado ellos romper[los] desde los principios de su erección". Con el recuento de las querellas que habían versado a propósito de la Colegiata se cerraba el pedimento, que tuvo un éxito inmediato. Ya el 13 de febrero de 1796 la Real Audiencia dictaba un auto favorable a la catedral, y aunque no habían sido notificados oficialmente aún, el día 15 los canónigos tenían ya conocimiento, y se ocupaban de expedir

52 Es el mismo argumento que hemos visto antes en el caso de Puebla, y que abundó también en los expedientes sobre el tema del honor de la paz, sobre todo en Guadalajara y en Valladolid de Michoacán. AGI, Guadalajara, leg. 379 para el primero y AGI, México, leg. 2662 para el segundo. 
agradecimientos al doctoral y a quienes se habían ocupado de "ver a los señores oidores" para interesarlos en el asunto. ${ }^{53}$

Así pues, hasta donde sabemos por las actas del Cabildo Catedral, en la ciudad de México hasta la época de la independencia los canónigos de la metropolitana lograron mayormente imponer su preeminencia con el uso de sus sillas, por encima de las otras corporaciones religiosas de la ciudad episcopal. Esto gracias al apoyo tanto del arzobispo como de la Real Audiencia, autoridades que confirmaron esa jerarquía del clero secular, que se hacía visible en el uso de las sillas en los presbiterios.

\section{Comentarios finales}

Durante el siglo XVIII, el asiento de los canónigos en sillas en los presbiterios de las iglesias fuera de las catedrales y en ellas incluso durante las ceremonias pontificales, aunque no debemos olvidar que tenían su justificación tal vez más fundamental en la diferencia entre el clero y los seglares, como lo señaló en su momento el fiscal marqués de Aranda, en realidad implicaban jerarquías más políticas que religiosas. Es cierto que, como lo afirmó el doctoral de la metropolitana, aparecen como símbolo de la posición de los canónigos en la jerarquía eclesiástica, de su superioridad respecto del resto del clero secular y como testimonio de que formaban un cuerpo con los obispos. Mas ya lo hemos visto: esos argumentos de inmediato se mezclaban con otros que fueron esgrimidos también por los magistrados reales y ayuntamientos, que cuestionaban o ambicionaban para sí esas sillas como la retribución que les correspondía en virtud de sus méritos personales y corporativos y para la utilidad pública. En ese sentido, antes y aún durante la época de las reformas, las sillas hacían visible ciertamente la religiosa superioridad del clero sobre los laicos, pero de manera particular el honor de los cabildos catedrales, por encima de las otras corporaciones y autoridades urbanas, y por tanto en perjuicio de esos otros actores de la vida política y religiosa de las ciudades episcopales novohispanas. Ni siquiera los reformadores borbónicos llegaron a cuestionar esa función.

En efecto, puede parecer contradictorio, en un siglo en que sabemos que el Patronato de los reyes se volvió "Patronato Universal", y en que la historiografía reciente ha insistido que el regalismo se impuso, el $\mathrm{Pa}$ tronato, si bien tenía un papel en las querellas, no era necesariamente decisivo. A pesar de que las sillas eran incluidas por los comentaristas entre los honores del patrono, y a pesar de que las propias autoridades

53 ACCMM, Actas de Cabildo, 1. 58, ff. 261v-262 y 264v. 
reales ambicionaran su uso, prefirieron mantenerlas limitadas a ciertos magistrados, como vemos en la negativa de extenderlas a alcaldes mayores y ayuntamientos. Los canónigos llegaron a alegar que las sillas eran un privilegio que les otorgaba el rey como patrono, pero evidentemente nunca se impuso como único argumento, y la propia majestad del monarca no llegó a imponer reglas fijas definitivas en la materia más allá de la legislación indiana, que como hemos visto más bien respaldaba la costumbre.

En ese sentido, pues, esas sillas que literalmente se alzaban sobre los presbiterios de las iglesias en sus fiestas principales, hasta finales del antiguo régimen e incluso durante las reformas borbónicas, siguieron recordando a los habitantes del reino de la Nueva España, aunque suene paradójico, cuán religioso era el orden político vigente.

\section{Siglas y referencias}

ACCM Archivo del Cabildo Catedral Metropolitano de México.

AGI Archivo General de Indias.

\section{Fuentes y bibliografía.}

Cañeque, A. (2004)

"De sillas y almohadones o de la naturaleza ritual del poder en la Nueva España de los siglos XVII y XVIII". Revista de Indias, 232, pp. 609-634.

Caeremoniale Episcoporum. (1837)

Nápoles: Tipografía Simoniana.

Concilio III Provincial Mexicano. (1859)

México: Eugenio Maillefert y Compañía editores.

Estatutos ordenados por el Santo Concilio III Provincial Mexicano. (1859). México: Imprenta de Vicente G. Torres.

Fogel, M. (1989)

Les cérémonies de l'information dans la France du XVIe au XVIIIe siècle.

París: Fayard.

Lempérière, A. (1998)

"República y publicidad a finales del Antiguo Régimen (Nueva España)". En F.-X. Guerra y A. Lempérière (coord.) Los espacios públicos en Iberoamérica. Ambigüedades y problemas. Siglos XVIII-XIX. México: Fondo de Cultura Económica, Centro de Estudios Mexicanos y Centroamericanos, pp. 54-79.

Mazín, O. (1996)

El cabildo catedral de Valladolid de Michoacán. Zamora: El Colegio de Michoacán. 
Mazín, O. (1999)

"La catedral de Valladolid y su cabildo eclesiástico", en N. Sigaut (coord.), La catedral de Morelia. Zamora: El Colegio de Michoacán, pp. 17-63.

Murillo Velarde, P. (2004)

Curso de derecho canónico hispano e indiano. Vol. 1. Zamora: El Colegio de Michoacán, Universidad Nacional Autónoma de México-Facultad de Derecho.

Ramos, F. (2010)

"Negociar el poder y reafirmar la fe en la Puebla del siglo XVIII. Los cabildos y la solución de los conflictos en el ámbito ceremonial", en F. X. Cervantes Bello (coord.), La Iglesia en la Nueva España: relaciones económicas e interacciones políticas. Puebla: Benemérita Universidad Autónoma de Puebla, pp. 257-289.

Recopilación de las leyes de los reynos de las Indias, en Archivo Digital de la Legislación del Perú. Consultado 15 de julio de 2015. http:// www.leyes.congreso.gob.pe/leyes_indias.aspx

Rivadeneyra, A. (1755)

Manual compendio del Regio Patronato Indiano. Madrid: Antonio Marín. 